This article was downloaded by: [The University of Manchester]

On: 04 April 2012, At: 07:03

Publisher: Psychology Press

Informa Ltd Registered in England and Wales Registered Number: 1072954

Registered office: Mortimer House, 37-41 Mortimer Street, London W1T 3J H, UK

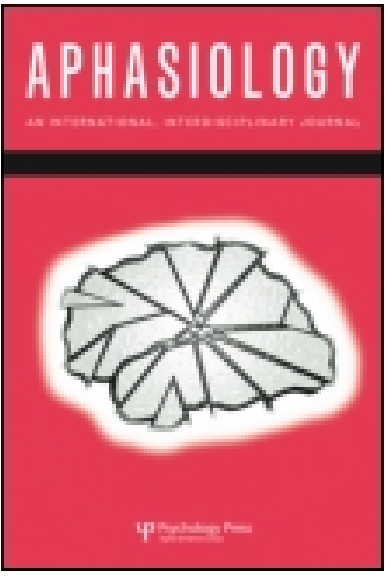

\title{
Aphasiology
}

Publication details, including instructions for authors and subscription information:

http:// www.tandfonline.com/loi/ paph20

\section{An emergent effect of phonemic cueing following relearning in semantic dementia}

Emily J. Mayberry ${ }^{a}$, Karen Sage ${ }^{a}$, Sheeba Ehsan ${ }^{a} \&$ Matthew

A. Lambon Ralph ${ }^{\text {a }}$

a School of Psychological Sciences, University of Manchester, UK

Available online: 12 Aug 2011

To cite this article: Emily J. Mayberry, Karen Sage, Sheeba Ehsan \& Matthew A. Lambon Ralph (2011): An emergent effect of phonemic cueing following relearning in semantic dementia, Aphasiology, 25:9, 1069-1077

To link to this article: http:// dx.doi.org/ 10.1080/ 02687038.2011.575203

\section{PLEASE SCROLL DOWN FOR ARTICLE}

Full terms and conditions of use: http://www.tandfonline.com/page/terms-andconditions

This article may be used for research, teaching, and private study purposes. Any substantial or systematic reproduction, redistribution, reselling, loan, sub-licensing, systematic supply, or distribution in any form to anyone is expressly forbidden.

The publisher does not give any warranty express or implied or make any representation that the contents will be complete or accurate or up to date. The accuracy of any instructions, formulae, and drug doses should be independently verified with primary sources. The publisher shall not be liable for any loss, actions, claims, proceedings, demand, or costs or damages whatsoever or howsoever caused arising directly or indirectly in connection with or arising out of the use of this material. 


\title{
An emergent effect of phonemic cueing following relearning in semantic dementia
}

\author{
Emily J. Mayberry, Karen Sage, Sheeba Ehsan, \\ and Matthew A. Lambon Ralph
}

School of Psychological Sciences, University of Manchester, UK

\begin{abstract}
Background: Semantic dementia (SD) is a disorder that leads to a gradual but profound breakdown of conceptual knowledge and, as a result, severe anomia that is not alleviated by phonemic cueing. Several studies have shown that practising to name a set of objects can help people with SD to relearn the names of those objects. However, it is not clear whether the factors that impact on spontaneous naming in SD would remain the same or whether they would change as a result of relearning.

Aims: The current relearning study examined phonemic cueing before and after relearning, to determine whether this factor's impact on naming changed during the course of the relearning.

Methods \& Procedures: Two people with SD participated in the study. A baseline naming test was performed prior to the start of the relearning. The relearning took place over 3 weeks (15 sessions), followed immediately by a retest the following day. Relearning and the influence of phonemic cueing were measured at baseline and retest.

Outcomes \& Results: The impact of phonemic cueing was greater at retest than at baseline.

Conclusions: Although phonemic cueing did not impact on spontaneous naming in SD, it did have a facilitative effect after relearning. This change may signal a shift in the relative contributions of the underlying learning systems.
\end{abstract}

Keywords: Semantic dementia; Relearning; Cueing.

\section{SEMANTIC DEMENTIA}

Semantic dementia (SD) is the temporal lobe variant of frontotemporal dementia and it is associated with progressive atrophy focused on the inferior and lateral portions of the anterior temporal lobes (ATL) (Galton et al., 2001; Mummery et al., 2000; Nestor, Fryer, \& Hodges, 2006) and gradual but profound, selective degradation of semantic knowledge across all sensory modalities. Other cognitive skills and episodic memory remain relatively preserved (Bozeat, Lambon Ralph, Patterson, Garrard, \& Hodges, 2000; Hodges, Patterson, Oxbury, \& Funnell, 1992; Piwnica-Worms, Omar,

Address correspondence to: Dr Karen Sage, Neuroscience and Aphasia Research Unit (NARU), Zochonis Building, School of Psychological Sciences, University of Manchester, Oxford Road, Manchester, M13 9PL, UK. E-mail: karen.sage@manchester.ac.uk

We would like to thank the people with semantic dementia for taking part in this study, and their families for their support. EJM was supported by an Overseas Research Student (ORS) Award and the University of Manchester. This project was supported by an MRC programme grant to MALR (G0501632).

(C) 2011 Psychology Press, an imprint of the Taylor \& Francis Group, an Informa business http://www.psypress.com/aphasiology

DOI: $10.1080 / 02687038.2011 .575203$ 
Hailstone, \& Warren, 2010; Snowden, Goulding, \& Neary, 1989; Warrington, 1975). The semantic impairment that occurs in SD leads to a severe anomia and, unlike in some people with anomia, the naming deficit in SD is not alleviated by phonemic cueing (Jefferies \& Lambon Ralph, 2006; Jefferies, Patterson, \& Lambon Ralph, 2008).

A number of studies have now charted the attempts of individuals with SD to regain and/or maintain verbal labels to show that some relearning is possible (e.g., Graham, Patterson, Pratt, \& Hodges, 1999, 2001; Green Heredia, Sage, Lambon Ralph, \& Berthier, 2009; Jokel, Rochon, \& Leonard, 2006; Snowden \& Neary, 2002). However, the factors that impact upon name relearning in SD have received less attention (e.g., Graham, Patterson, Pratt, \& Hodges, 1999, 2001; Green Heredia et al., 2009; Jokel et al., 2006; Snowden \& Neary, 2002). What occurs in the underlying systems during relearning may be better understood by comparing what impacts on naming following relearning with what is known to impact on spontaneous naming. The current study will focus on measuring the impact of one factor - phonemic cueing — both before and after relearning.

\section{RELEARNING IN SD: PREVIOUS STUDIES}

To date there have been 12 SD relearning studies (Bier et al., 2009; Dewar, Patterson, Wilson, \& Graham, 2009; Frattali, 2004; Funnell, 1995; Graham, Patterson, Pratt, \& Hodges, 1999, 2001; Henry, Beeson, \& Rapcsak, 2008; Green Heredia et al., 2009; Jokel, Rochon, \& Anderson, 2010; Jokel et al., 2006; Robinson, Druks, Hodges, \& Garrard, 2009; Snowden \& Neary, 2002). Typically, with sufficient regular practice people with SD can relearn object names for items they study, but learning is very rigid (Bier et al., 2009; Graham, Patterson, Pratt, \& Hodges, 1999; Green Heredia et al., 2009; Jokel et al., 2006, 2010; Robinson et al., 2009; Snowden \& Neary, 2002). For example, participant $\mathrm{CR}$ was able to relearn the names of a set of items but naming accuracy dropped when the same items were presented in a random order (rather than in the studied order) and on single sheets of blue paper (rather than within a booklet of white paper) (Snowden \& Neary, 2002). In other words, the relearning was highly dependent on the relearning context.

Exactly what occurs in the brain during relearning in SD is not yet clear. One possibility is that practising with object names leads to a partial retraining of concepts within the degraded semantic system such that the concept representations are strengthened in a similar fashion to the way they were originally formed. If this is the case, then the same factors that predict naming prior to relearning might be expected to impact on naming after relearning. Alternatively, if there is a shift towards more reliance on a supplementary episodic learning system which builds up sparse, rigid representations (McClelland, McNaughton, \& O’Reilly, 1995; Graham, Patterson, \& Hodges, 1999; Snowden \& Neary, 2002), then the factors that impact on naming after relearning might be different.

\section{PHONEMIC CUEING IN SD: BEFORE AND AFTER RELEARNING}

Semantic degradation in SD is gradual but once the ATL representation for a concept falls below a certain threshold, it is too weak to activate no matter how it is probed (Jefferies \& Lambon Ralph, 2006; Jefferies et al., 2008; Warrington \& Cipolotti, 1996). This means that people with SD exhibit a high degree of consistency for a given 
concept across different tasks (Jefferies \& Lambon Ralph, 2006). It also means that phonemic cueing, even with nearly whole word cues, is not effective at facilitating naming in SD (Jefferies \& Lambon Ralph, 2006; Jefferies et al., 2008).

In contrast to spontaneous naming there is some limited evidence to suggest that phonemic cueing may be beneficial to people with SD after relearning. Snowden and Neary (2002) tested the effect of orthographic cues (written presentation of first letter or first syllable depending on word length) before and after relearning in a person with SD and found no effect at baseline. However, at a follow-up several months after the relearning had ceased, the person with SD spontaneously named 13 of the 20 trained items and the written cues facilitated naming of the remaining seven items. The current study aims to study the cueing effect in more detail in order to determine whether or not the effect of phonemic cueing changes from baseline to retest.

\section{METHOD}

\section{Participants}

Two people (NH and GE) with a diagnosis of SD were recruited from a local memory clinic. Table 1 provides a behavioural profile outlining their semantic impairments and other, relatively spared, cognitive abilities. Both participants had brain scans typical of SD with bilateral atrophy focused on the inferior and lateral ATLs. NH's semantic impairment was milder than that of GE, which was in line with her more recent diagnosis.

\section{Stimuli}

A 64-item naming test (Lambon Ralph, Howard, Nightingale, \& Ellis, 1998) was used in the current study. The average score on this task for eight adults with an average age of 68.4 and 10 years of education was 62.75/64. A 64-item word-to-picture matching task containing these same 64 items was also created, with foils selected from other items in the test. For the matching task each trial contained one target and five foils all within the same category (living or nonliving) as the target.

Once baseline naming of the 64 items had been carried out, the items were split into a trained and an untrained set of 32 items. Trained and untrained sets for each participant were matched for the variables which are known to affect naming in SD lexical frequency as measured by CELEX (Baayen, Piepenbrock, \& van Rijn, 1993) and baseline knowledge (Jokel et al., 2006; Snowden \& Neary, 2002). Individual baseline naming and individual baseline word-to-picture matching were used to determine this variable.

\section{Procedure}

Baseline. NH and GE were visited at home and the 64-item naming test was carried out, followed by the word-to-picture matching test for the 64 items. During the naming test, when $\mathrm{NH}$ or GE was unable to name an item spontaneously, the first phoneme of the word was given as a phonemic cue. Spontaneous responses and responses after cues were recorded.

Training. NH and GE were each given a booklet which contained their individualised 32 items to study. For all 32 items the first page displayed a picture of the item 
TABLE 1

Background neuropsychological testing

\begin{tabular}{|c|c|c|c|c|}
\hline & & & $N H$ & $G E$ \\
\hline Age & & & 65 & 52 \\
\hline \multicolumn{3}{|l|}{ Sex } & $\mathrm{F}$ & M \\
\hline \multirow[t]{2}{*}{ Scan } & & & $\begin{array}{r}\mathrm{R}>\mathrm{L} \text { ATL } \\
\text { atrophy }\end{array}$ & $\begin{array}{c}\mathrm{L}>\mathrm{R} \text { ATL } \\
\text { atrophy }\end{array}$ \\
\hline & Max score & $\begin{array}{l}\text { Normal } \\
\text { cut-off / } \\
\text { range }\end{array}$ & $\mathrm{NH}$ & $G E$ \\
\hline \multicolumn{5}{|l|}{ Semantic tests } \\
\hline 64 Naming & 64 & 59 & $24^{*}$ & $14^{*}$ \\
\hline 64 WPM & 64 & 63 & $37^{*}$ & $34^{*}$ \\
\hline PPT Pictures & 52 & 49 & NT & $35^{*}$ \\
\hline PPT Words & 52 & 49 & NT & $33^{*}$ \\
\hline CCT Pictures & 64 & 53 & $41^{*}$ & $25^{*}$ \\
\hline CCT Words & 64 & 56 & NT & $22^{*}$ \\
\hline Category Fluency (8 categories) & $\mathrm{n} / \mathrm{a}$ & 89 & $14^{*}$ & $22^{*}$ \\
\hline \multicolumn{5}{|l|}{ Other cognitive tests } \\
\hline Ravens Coloured Progressive Matrices & 36 & $\%$ ile & $25^{\text {th }} \%$ ile & $>95^{\text {th }} \%$ ile \\
\hline Rey Immediate Recall & 36 & $\%$ ile & NT & $>99^{\text {th }} \%$ ile \\
\hline Digit span (forward) & $\mathrm{n} / \mathrm{a}$ & 5 & $4^{*}$ & 7 \\
\hline Letter Fluency & $\mathrm{n} / \mathrm{a}$ & 22 & 34 & $19^{*}$ \\
\hline VOSP Dot counting & 10 & 8 & 10 & 10 \\
\hline VOSP Position discrimination & 20 & 18 & $16^{*}$ & 20 \\
\hline VOSP Number location & 10 & 7 & 10 & 10 \\
\hline VOSP Cube analysis & 10 & 6 & 9 & 10 \\
\hline TEA elevator counting (without distraction) & 7 & 6 & 7 & 7 \\
\hline TEA elevator counting (with distraction) & 10 & 3 & 9 & 10 \\
\hline
\end{tabular}

$\mathrm{F}=$ female, $\mathrm{M}=$ male, $\mathrm{R}=$ right hemisphere, $\mathrm{L}=$ left hemisphere, $\mathrm{ATL}=$ anterior temporal lobes, $\mathrm{NT}=$ not tested, ${ }^{*}$ participant score below the normal cut-off.

64 Naming $=$ Cambridge 64-item naming test (Bozeat et al., 2000), 64 WPM $=$ Cambridge 64-item word-to-picture matching (Bozeat et al., 2000), PPT $=$ Three-picture Pyramids and Palm Trees (Howard \& Patterson, 1992), CCT $=$ Cambridge 64-item Camel and Cactus test of semantic association (Bozeat et al., 2000), Category Fluency = concepts (eight tested) produced in 1 minute, Ravens Coloured Progressive Matrices (Raven, 1962), Complex Figure of Rey immediate recall subtest (Osterreith, 1995), Digit span (Wechsler, 1987), Letter fluency $=$ words beginning with F, A, and S in one minute, VOSP $=$ Visual Object and Space Perception Battery (Warrington \& James, 1991), TEA = Test of Everyday Attention elevator counting subtests, with and without distraction (Robertson, Ward, Ridgeway, \& Nimmo-Smith, 1994)

and the next page displayed the same picture with the written label underneath. For each study session each participant opened the booklet to the first page and attempted to name the item. If they were unable to name it they were asked to turn to the next page and read the name aloud while focusing on the picture. They did this once for each of the 32 items in the booklet. After the initial face-to-face learning session $\mathrm{NH}$ and GE were telephoned each day for 3 weeks (15 sessions in total). They followed the same procedure for each session and their learning profiles were recorded each day.

Retest. The day after the end of the 15 training sessions, NH and GE were visited at home to reassess their skills in naming and word-to-picture matching for all the 
64 items. The reassessments were carried out in the same way that they had been at baseline; that is, the items were in the same order as the baseline testing with the 32 trained items randomly distributed throughout the set. During naming, when either participant could not name an item spontaneously a phonemic cue was given.

\section{RESULTS}

\section{Overall naming: Effects of relearning}

Spontaneous (uncued) naming performance is shown in Figure 1 for NH (1a) and GE (1b). NH improved her naming of trained items significantly from a baseline score of $8 / 32(25 \%)$ to a retest score of 29/32 (90.6\%) (McNemar, two-tailed, $p<.001)$. For the untrained items NH did not show any change in naming, with a baseline score of $9 / 32(28.13 \%)$ and a retest score of $7 / 32(21.88 \%)$ (McNemar, two-tailed, $p=.625)$. GE also improved his naming of trained items significantly from a baseline score of $1 / 32(3.13 \%)$ to a retest score of $13 / 32(40.63 \%)$ (McNemar, two-tailed, $p<.001)$. For the untrained items GE did not show any change in naming, with a baseline score of $2 / 32(6.25 \%)$ and a retest score of 3/32 (9.38\%) (McNemar, two-tailed, $p=1.000)$.

(a)

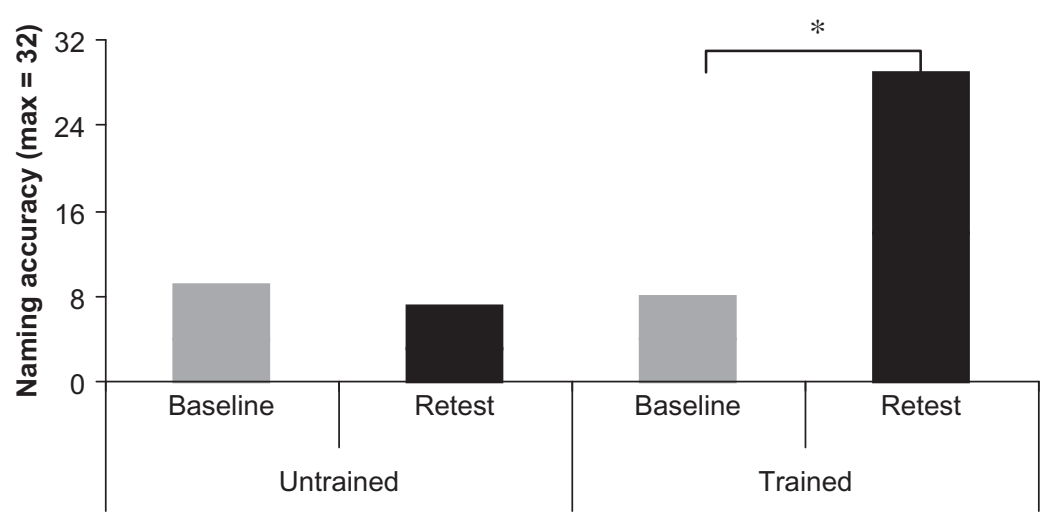

(b)

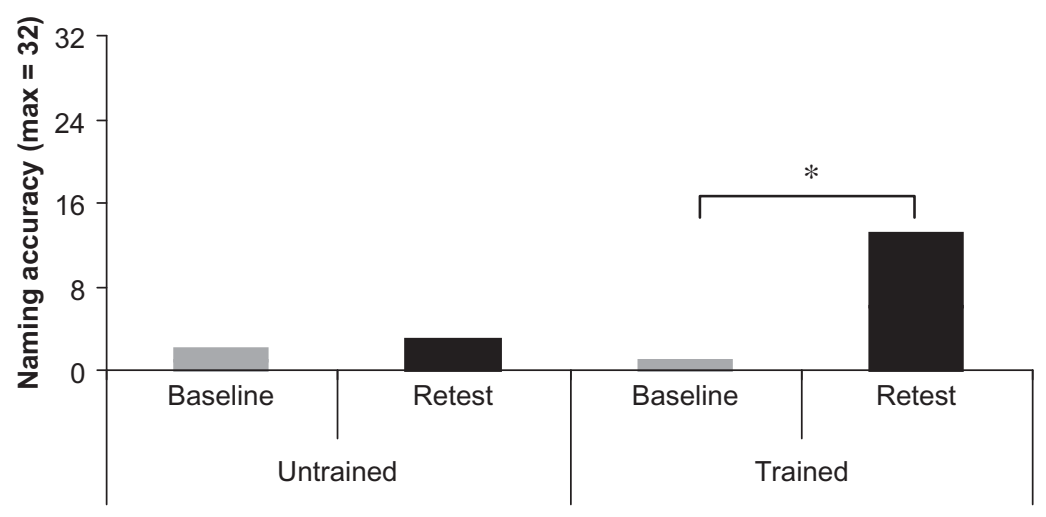

Figure 1. Baseline and retest naming performance for NH (1a) and GE (1b). ${ }^{*} p<.05$. 


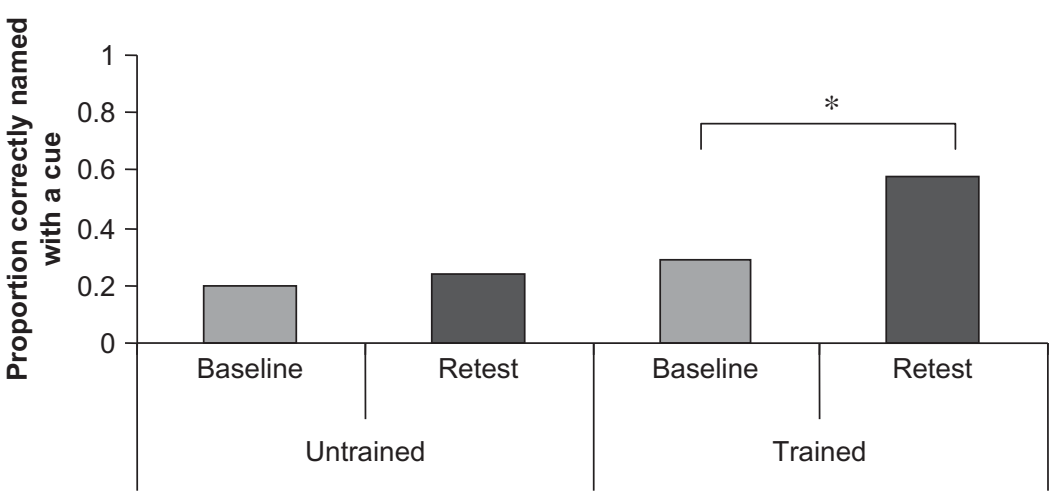

Figure 2. Effect of phonemic cueing on unnamed items before and after training (participant GE). ${ }^{*} p<.05$.

\section{Influence of phonemic cueing}

At retest NH spontaneously named all but 3 of the 32 trained items, so it was not possible to compare the relative facilitative effect of phonemic cueing at baseline $(1 / 24)$ versus retest (2/3) for her. On the other hand, at baseline GE named 1 out of the 32 trained items without a cue (which left 31 available to cue) and 13 of the 32 trained items without a cue at retest (which left 19 available to cue). Therefore it was possible to carry out a comparison of the proportion of trials where a cue helped GE to name an item at baseline versus retest. There was a significant difference between the two time points, with cues facilitating naming on a larger proportion of trials at retest $(11 / 19,57.9 \%)$ than at baseline $(9 / 31,29.0 \%) \chi^{2}(d f=1)=4.089, p=.043$. For the untrained concepts there was no difference in cueing benefit from baseline $(6 / 30$, $20.0 \%$ ) to retest $(7 / 29,24.1 \%) \chi^{2}(d f=1)=0.147, p=.701$ (see Figure 2 ).

\section{DISCUSSION}

Two people with SD showed the typical pattern when relearning; they improved from baseline to retest at naming the trained items but they did not improve their naming of untrained items. The current study also measured the impact of phonemic cueing before and after relearning and, although phonemic cueing has very little, if any, facilitative effect on spontaneous naming in SD (Corbett, Jefferies, \& Lambon Ralph, 2008; Jefferies \& Lambon Ralph, 2006; Jefferies et al., 2008), this study found cueing to have more of an effect after relearning than before.

The Complementary Learning Systems (CLS) theory (McClelland et al., 1995) provides a useful framework for interpreting the results of previous relearning studies and the results of the current investigation. The CLS theory suggests that there are separate but interactive brain regions involved in learning: a medial temporal lobe (MTL) system and a neocortical system. Although these two systems are hypothesised to be highly interactive, there is a wealth of evidence to show that each system represents information in a different way and therefore serves a distinct function in learning. Specifically, the representations formed in the MTL system are sparse and, consequently situations that differ only slightly may share relatively little representational overlap (Marr, 1969; McNaughton \& Morris, 1987; Randall \& James, 1994). This allows for specific pieces of information to be captured quickly and stored relatively 
independently from other memories (so it is possible to distinguish between two very similar but different recent episodes) but, as a consequence, it does not allow for similarities between different items or experiences to be captured. Damage to this region leads to impaired learning of new information (anterograde amnesia) but does not interfere with existing stores of semantic knowledge (Scoville \& Milner, 1957). Such distributed representations license appropriate generalisations based on the deeper semantic structure and not on the basis of surface features and the learning context (Lambon Ralph, Sage, Jones, \& Mayberry, 2010; Lambon Ralph \& Patterson, 2008; McClelland et al., 1995).

Previous SD relearning studies have found that people with SD are able to relearn the specific information that they study but this relearning is very rigid. Specifically, there has been very little generalisation of the relearned information to untrained items or untrained tasks ( Frattali, 2004; Graham, Patterson, Pratt, \& Hodges, 1999, 2001; Snowden \& Neary, 2002) and the relearning has been highly dependent on contextual cues (Bier et al., 2009; Graham, Patterson, Pratt, \& Hodges, 1999, 2001; Robinson et al., 2009; Snowden \& Neary, 2002). These studies have interpreted such findings to mean that there is an increased reliance on the rigid MTL learning system and less interaction with the damaged semantic system (Graham, Patterson, Pratt, \& Hodges, 1999, 2001; Snowden \& Neary, 2002).

The current results further support the view that there is a shift away from the normal interaction of the two learning systems in SD. If the degraded (cortical) semantic system was making a considerable contribution to relearning then one might expect the same performance factors to show up in the relearning results. However, finding an increase in the effect of phonemic cueing following relearning suggests that the factors that influence naming following relearning may have changed. Future studies would need to determine whether the impact of any other factors has changed. The results of the current study provide the first hint that this may be the case.

It is possible, however, that the specific relearning paradigm used in the current study encouraged episodic rather than semantic learning. Asking the participants to link a particular label to a particular picture could be achieved through the build-up of sparse hippocampal representations and therefore may not require the participants to fully engage the semantic system in the relearning. Future relearning studies might explore whether or not paradigms that include multiple exemplars of the concepts and/or information from multiple sensory modalities (e.g., using real items as well as pictures, carrying out different tasks with the objects/pictures etc.) can encourage further semantic engagement in the relearning in order to lead to better outcomes.

Although there may be a shift in the division of labour as a result of relearning, this does not necessarily mean that the degraded neocortical semantic system is entirely uninvolved. In fact there is some evidence that the semantic system is still engaged when people with SD relearn. The first source of evidence comes from nonrelearning studies which have shown that concepts are not lost wholesale in SD but rather the representations deteriorate in a graded fashion and continue to engage in semantic tasks (Hodges, Graham, \& Patterson, 1995; Rogers et al., 2004; Warrington, 1975). Second, SD participants demonstrate better relearning of names for which they have more baseline conceptual knowledge (Graham et al., 2001; Jokel et al., 2006; Snowden \& Neary, 2002) and more recent studies have demonstrated that, if tested with the right set of materials, people with SD overgeneralise as well as undergeneralise the relearned information (Mayberry, Sage, Ehsan, \& Lambon Ralph, 2011). While undergeneralisation could be explained by an over-reliance on the MTL learning 
system (e.g., Graham, Patterson, Pratt, \& Hodges, 1999, 2001; Snowden \& Neary, 2002), the sparse representations built up in this system would not allow for generalisation (or the overgeneralisation) which has now been demonstrated (Mayberry et al., 2011). When all of these studies are considered together, the emerging conclusion is that there continues to be an interaction between the two learning systems but that the division of labour is shifted more towards the intact MTL system and away from the ATL semantic component during relearning in SD.

The results of the current study suggest that cueing could be a useful way to measure which items were beginning to respond to training but had not yet received sufficient training to support (uncued) spontaneous naming. If this were the case, then this would suggest that cueing could be used as an indicator for additional training. However, those concepts that respond to phonemic cueing are likely to be supported by a rigid, episodic learning system and therefore generalisation may still be limited. Future relearning studies might consider ways not only of boosting the degraded concepts themselves but also of shifting the division of labour back towards its normal balance, possibly through more interactive, multimodal learning paradigms.

\footnotetext{
Manuscript received 18 February 2011 Manuscript accepted 22 March 2011
}

\section{REFERENCES}

Baayen, R. H., Piepenbrock, R., \& van Rijn, H. (1993). The CELEX lexical database [CD-ROM]. Philadelphia, PA: Linguistics Data Consortium, University of Pennsylvania.

Bier, N., Macoir, J., Gagnon, L., Van der Linden, M., Louveaux, S., \& Desrosiers, J. (2009). Known, lost, and recovered: Efficacy of formal-semantic therapy and spaced retrieval method in a case of semantic dementia. Aphasiology, 23(2), 210-235.

Bozeat, S., Lambon Ralph, M. A., Patterson, K., Garrard, P., \& Hodges, J. R. (2000). Non-verbal semantic impairment in semantic dementia. Neuropsychologia, 38, 1207-1215.

Corbett, F., Jefferies, E., \& Lambon Ralph, M. A. (2008). The use of cueing to alleviate recurrent verbal perseverations: Evidence from transcortical sensory aphasia. Aphasiology, 22(4), 363-382.

Dewar, B-K., Patterson, K., Wilson, B. A., \& Graham, K. S. (2009). Re-acquisition of person knowledge in semantic memory disorders. Neuropsychological Rehabilitation, 19(3), 383-421.

Frattali, C. (2004). An errorless learning approach to treating dysnomia in frontotemporal dementia. Journal of Medical Speech-Language Pathology, 12(3), XI-XXIV.

Funnell, E. (1995). A case of forgotten knowledge. In R. Campbell \& M. Conway (Eds.), Broken memories: Case studies in memory impairment (pp. 225-236). Oxford, UK: Blackwell.

Galton, C. J., Patterson, K., Graham, K. S., Lambon Ralph, M. A., Williams, G., Antoun, N., et al. (2001). Differing patterns of temporal atrophy in Alzheimer's disease and semantic dementia. Neurology, 57, $216-225$.

Graham, K. S., Patterson, K., \& Hodges, J. R. (1999). Episodic memory: New insights from the study of semantic dementia. Current Opinion in Neurobiology, 9, 245-250.

Graham, K. S., Patterson, K., Pratt, K. H., \& Hodges, J. R. (1999). Relearning and subsequent forgetting of semantic category exemplars in a case of semantic dementia. Neuropsychology, 13(3), 359-380.

Graham, K. S., Patterson, K., Pratt, K. H., \& Hodges, J. R. (2001). Can repeated exposure to "forgotten" vocabulary help alleviate word-finding difficulties in semantic dementia? An illustrative case study. Neuropsychological Rehabilitation, 11(3-4), 429-454.

Green Heredia, C. G., Sage, K., Lambon Ralph, M. A., \& Berthier, M. (2009). Relearning and retention of verbal labels in a case of semantic dementia. Aphasiology, 23, 192-209.

Henry, M. L., Beeson, P. M., \& Rapcsak, S. Z. (2008). Treatment for lexical retrieval in progressive aphasia. Aphasiology, 22(7-8), 826-838.

Hodges, J. R., Graham, N., \& Patterson, K. (1995). Charting the progression of semantic dementia: Implications for the organisation of semantic memory. Memory, 3, 463-495.

Hodges, J. R., Patterson, K., Oxbury, S., \& Funnell, E. (1992). Semantic dementia: Progressive fluent aphasia with temporal lobe atrophy. Brain, 115(Pt6), 1783-1806. 
Howard, D., \& Patterson, K. (1992). The Pyramids and Palm Trees Test: A test of semantic access from words and pictures. Bury St. Edmunds, UK: Thames Valley Test Company.

Jefferies, E., \& Lambon Ralph, M. A. (2006). Semantic impairment in stroke aphasia vs. semantic dementia: A case-series comparison. Brain, 129, 2132-2147.

Jefferies, E., Patterson, K., \& Lambon Ralph, M. A. (2008). Deficits of knowledge versus executive control in semantic cognition: Insights from cued naming. Neuropsychologia, 46(2), 649-658.

Jokel, R., Rochon, E., \& Anderson, N. D. (2010). Errorless learning of computer-generated words in a patient with semantic dementia. Neuropsychological Rehabilitation, 20(1), 16-41.

Jokel, R., Rochon, E., \& Leonard, C. (2006). Treating anomia in semantic dementia: Improvement, maintenance, or both? Neuropsychological Rehabilitation, 16, 241-256.

Lambon Ralph, M. A., Howard, D., Nightingale, G., \& Ellis, A. W. (1998). Are living and non-living category-specific deficits causally linked to impaired perceptual or associative knowledge? Evidence from a category-specific double dissociation. Neurocase, 4, 311-338.

Lambon Ralph, M. A., \& Patterson, K. (2008). Generalization and differentiation in semantic memory: Insights from semantic dementia. In A. Kingstone \& M. Miller (Eds.), The year in cognitive neuroscience. New York: Annals of the NY Academy of Sciences.

Lambon Ralph, M. A., Sage, K., Jones, R. W., \& Mayberry, E. J. (2010). Coherent concepts are computed in the anterior temporal lobes. Proceedings of the National Academy of Sciences, 107(6), 2717-2722.

Marr, D. (1969). A theory of cerebellar cortex. The Journal of Physiology, 202(2), 437-470.

Mayberry, E. J., Sage, K., Ehsan, S., \& Lambon Ralph, M. A. (2011). Relearning in semantic dementia reflects contributions from both medial temporal lobe episodic and degraded neocortical semantic systems: Evidence in support of the complementary learning systems theory. Manuscript submitted for publication.

McClelland, J. L., McNaughton, B. L., \& O'Reilly, R. C. (1995). Why there are complementary learningsystems in the hippocampus and neocortex: Insights from the successes and failures of connectionist models of learning and memory. Psychological Review, 102(3), 419-457.

McNaughton, B. L., \& Morris, R. G. M. (1987). Hippocampal synaptic enhancement and information storage within a distributed memory system. Trends in Neurosciences, 10(10), 408-415.

Mummery, C. J., Patterson, K., Price, C. J., Ashburner, J., Frackowiak, R. S. J., \& Hodges, J. R. (2000). A voxel based morphometry study of semantic dementia: The relation of temporal lobe atrophy to cognitive deficit. Annals of Neurology, 47, 36-45.

Nestor, P. J., Fryer, T. D., \& Hodges, J. R. (2006). Declarative memory impairments in Alzheimer's disease and semantic dementia. Neuroimage, 30(3), 1010-1020.

Osterreith, P. (1995). Complex figure of Rey (3rd ed.). Oxford, UK: Oxford University Press.

Piwnica-Worms, K. E., Omar, R., Hailstone, J. C., \& Warren, J. D. (2010). Flavour processing in semantic dementia. Cortex, 46(6), 761-768.

Randall, C. O. R., \& James, L. M. (1994). Hippocampal conjunctive encoding, storage, and recall: Avoiding a trade-off. Hippocampus, 4(6), 661-682.

Raven, J. C. (1962). Coloured progressive matrices: Sets A, AB, B. London: HK Lewis.

Robertson, I., Ward, T., Ridgeway, V., \& Nimmo-Smith, I. (1994). The Test of Everyday Attention. Bury St Edmunds, UK: Thames Valley Test Company.

Robinson, S., Druks, J., Hodges, J., \& Garrard, P. (2009). The treatment of object naming, definition, and object use in semantic dementia: The effectiveness of errorless learning. Aphasiology, 23(6), 749-775.

Rogers, T. T., Lambon Ralph, M. A., Garrard, P., Bozeat, S., McClelland, J. L., Hodges, J. R., et al. (2004). The structure and deterioration of semantic memory: A neuropsychological and computational investigation. Psychological Review, 111, 205-235.

Scoville, W. B., \& Milner, B. (1957). Loss of recent memory after bilateral hippocampal lesions. Journal of Neurology, Neurosurgery \& Psychiatry, 20(1), 11-21.

Snowden, J. S., Goulding, P. J., \& Neary, D. (1989). Semantic dementia: A form of circumscribed cerebral atrophy. Behavioural Neurology, 2(3), 167-182.

Snowden, J. S., \& Neary, D. (2002). Relearning of verbal labels in semantic dementia. Neuropsychologia, $40(10), 1715-1728$.

Warrington, E. K. (1975). The selective impairment of semantic memory. Quarterly Journal of Experimental Psychology, 27(4), 635-657.

Warrington, E. K., \& Cipolotti, L. (1996). Word comprehension: The distinction between refractory and storage impairments. Brain, 119, 611-625.

Warrington, E. K., \& James, M. (1991). The Visual Object and Space Perception battery. Bury St. Edmunds, UK: Thames Valley Test Company.

Wechsler, D. (1987). Wechsler Memory Scale-Revised (WMS-R). New York: Psychological Corporation. 